\title{
Cloning and Sequence Analysis of cDNA for Irpex lacteus Aspartic Proteinase
}

\author{
Hideyuki Kobayashi, Satoshi Sekibata, Hiroshi Shibuya, \\ Shigeki Yoshida, Isao KuSAKaBE \\ and Kazuo Murakaml \\ Institute of Applied Biochemistry, University of Tsukuba, \\ Ibaraki 305, Japan \\ Received January 31, 1989
}

\begin{abstract}
To find the primary sequence of Irpex lacteus aspartic proteinase (ILAP), a cDNA library of $I$. lacteus mRNA in pBR322 was constructed. A clone, which had an insert size of about 1.2 kilobase pairs, was found to contain the coding region of the mature enzyme. The deduced amino acid sequence showed that the enzyme consisted of 340 amino acid residues with a molecular weight of 35,000 . Cysteine and methionine were not found in the enzyme and two putative $N$-glycosylation sites were indicated. The lack of S-S bridges in the molecule is a striking feature of the enzyme. The alignment of the sequence of the enzyme against other aspartic proteinases revealed homology around the active site aspartic acid residues.
\end{abstract}

In the selection of a rennet substitute, the ratio of milk-clotting activity to proteolytic activity (MCA/PA) is an important index, and a higher $\mathrm{MCA} / \mathrm{PA}$ ratio is desirable. Irpex lacteus aspartic proteinase (ILAP) was most active at $\mathrm{pH} 3.0$ toward protein substrates and is inhibited by pepstatin, diazoacetyl-D,Lnorleucine methylester (DAN), and 1,2epoxy-3-( $p$-nitrophenoxy)propane (EPNP). ${ }^{1)}$ It had almost the same value of MCA/PA as commercial microbial milk-clotting enzymes from Mucor pusillus and M. miehei. In actual cheese-making trials, ILAP could produce some kinds of cheeses of good quality including fiber-structured cheese, ${ }^{2)}$ Gouda cheese, ${ }^{3)}$ and Cheddar cheese. ${ }^{4)}$ All of the milk-clotting enzymes used commercially belong to the aspartic proteinase family and they are homologous when the primary structures are aligned and compared with other aspartic proteinases. $^{5)}$ To get information on the structurefunction relationship of ILAP, the elucidation of its primary structure is necessary. We described here the nucleotide sequence of ILAP cDNA. The ILAP sequence shows significant overall homology to the aspartic proteinase family and strict conservation of essential residues around the two activesite aspartic acids.

\section{Materials and Methods}

DNA restriction and modification enzymes were from Takara Shuzo (Japan). Nitrocellulose filter was from Schleicher and Schuell. Oligo(dT)-cellulose (type III) was from Collaborative Research. ${ }^{32} \mathrm{P}$-labelled nucleotides were purchased from Amersham. Irpex lacteus (K Y2981) and its crude enzyme powder was kindly supplied by Kyowa Hakko Co., Ltd.

A medium containing 4\% sucrose, $3 \%$ distillers solubles, $0.3 \%$ yeast extract, $0.5 \% \mathrm{KH}_{2} \mathrm{PO}_{4}$, and $0.05 \%$ $\mathrm{MgSO}_{4} \cdot 7 \mathrm{H}_{2} \mathrm{O}, \mathrm{pH} 4.0$, was used for seed culture and a medium containing $6 \%$ sucrose, $3 \%$ distillers solubles, $0.6 \%$ yeast powder, $0.6 \% \mathrm{NH}_{4} \mathrm{H}_{2} \mathrm{PO}_{4}, 0.5 \% \mathrm{KH}_{2} \mathrm{PO}_{4}$, $0.05 \% \mathrm{MgSO}_{4} \cdot 7 \mathrm{H}_{2} \mathrm{O}, 0.1 \%$ lactic acid, $1 \mathrm{ppm}$ calcium pantothenate, $10 \mathrm{ppm}$ choline chloride, and $0.2 \%$ Nonion $\mathrm{E}-230, \mathrm{pH} 3.8$, was used for enzyme production.

Purification of ILAP. The purification procedures were done at $4^{\circ} \mathrm{C}$ unless otherwise indicated. Crude enzyme powder was dissolved in ice-cold $0.01 \mathrm{M}$ sodium acetate,

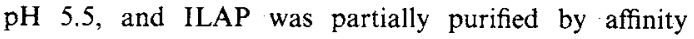
chromatography as described previously. ${ }^{1)}$ Fractions rich in ILAP were dialyzed against $0.02 \mathrm{M}$ sodium acetate, $\mathrm{pH}$ 4.6, and were put on a column of DEAE-Sepharose fast flow $(1.5 \times 30 \mathrm{~cm})$ equilibrated with the same buffer. ILAP 
was eluted from the column with a $\mathrm{pH}$ gradient from the buffer to $0.1 \mathrm{M}$ acetic acid. Main fraction was collected and put on a RP-HPLC column ( $\mathrm{C}_{8}$, Altex, $\left.4 \times 250 \mathrm{~mm}\right)$ equilibrated with $25 \mathrm{~mm}$ triethylamine-phosphate, $\mathrm{pH} 6.0$. ILAP was eluted as a single peak with a linear acetonitrile gradient from $0 \%$ to $90 \%$ and used as purified ILAP. This preparation was judged homogeneous by SDS-PAGE ${ }^{6}$ and $\mathrm{pH} 4.3 \mathrm{PAGE}^{7)}$ (data not shown).

Amino acid analysis. For determination of the amino acid composition, purified ILAP was hydrolyzed in $6 \mathrm{~N}$ $\mathrm{HCl}$ at $110^{\circ} \mathrm{C}$ for 24,48 , and $72 \mathrm{hr}$, and the hydrolyzate was analyzed with a Dionex amino acid analyzer model D5. Tryptophane was measured with $p$-toluenesulfonic acid by the method of Penke. ${ }^{8 \text { ? }}$

Preparation of 1 . lacteus $m R N A$. An agar block $(5 \times 5 \mathrm{~mm})$ containing $I$. lacteus hyphae from a slant culture was inoculated into $100 \mathrm{ml}$ of seed medium in a $500-\mathrm{ml}$ Sakaguchi flask and cultured at $30^{\circ} \mathrm{C}$ for 3 days with shaking. Then $5 \mathrm{ml}$ of this seed medium was inoculated into $100 \mathrm{ml}$ of enzyme production medium in a $500-\mathrm{ml}$ Sakaguchi flask and cultured at $30^{\circ} \mathrm{C}$ for 5 days. The mycelia were collected by filtration on No. 2 filter paper, washed with $\mathrm{H}_{2} \mathrm{O}$, frozen in liquid nitrogen and stored at $-70^{\circ} \mathrm{C}$ until use.

A mixture of $80 \mathrm{ml}$ of extraction buffer $(0.1 \mathrm{M}$ Tris- $\mathrm{HCl}$, $10 \mathrm{~mm}$ EDTA, $1 \%$ SDS, pH 9.0), $40 \mathrm{ml}$ of phenol saturated with the extraction buffer, and $40 \mathrm{ml}$ chloroform was added to $20 \mathrm{~g}$ of frozen mycelium, and homogenized at $15,000 \mathrm{rpm}$ for $3 \mathrm{~min}$ with a homogenizer (Ace, Japan). After centrifugation $\left(15,000 \times g, 20 \mathrm{~min}, 2^{\circ} \mathrm{C}\right)$ the aqueous phase $(92 \mathrm{ml})$ was recovered. RNA was selectively precipitated by making the aqueous phase $2 \mathrm{M}$ in $\mathrm{LiCl}$ and standing for more than $1 \mathrm{hr}$ at $2^{\circ} \mathrm{C}$. The precipitate was collected by centrifugation $\left(15,000 \times g, 15 \mathrm{~min}, 2^{\circ} \mathrm{C}\right)$, washed three times with $2 \mathrm{M} \mathrm{LiCl}$ and twice with $70 \%(\mathrm{v} / \mathrm{v})$ ethanol at $-20^{\circ} \mathrm{C}$. From the total RNA obtained $(36 \mathrm{mg})$, samples (14 mg) were put on an oligo(dT)-cellulose column and chromatographed. A messenger RNA fraction $(375 \mu \mathrm{g})$ was obtained and the recovery was estimated to be $2.7 \%$.

cDNA synthesis and screening of the cDNA library. Oligo(dT)-primer was elongated by reverse transcription of poly $\left(\mathrm{A}^{+}\right) \mathrm{RNA}$, and double-stranded cDNA was synthesized as described by Gubler and Hoffman. ${ }^{9)}$ The resulting double-stranded CDNA was treated with $T_{4}$ DNA polymerase to remove the remaining 3 '-end overhangs from the first-strand cDNA and inserted into the Pst I site of pBR 322 by the $(\mathrm{dG})-(\mathrm{dC})$ homopolymer extension method. ${ }^{10)}$ E. coli $\mathrm{DH}-1$ cells were transformed with the recombinant plasmids as described by Hanahan. ${ }^{11}$ The yield of transformants was about 10,000 . The cDNA library was screened for ILAP cDNA sequences by colony hydridization with ${ }^{32} \mathrm{P}$-labeled oligonucleotide probe.

Prehydridization and hybridization were done at $36^{\circ} \mathrm{C}$ in a solution containing $6 \times \mathrm{SSC}, 0.5 \% \mathrm{SDS}$, $5 \times$ Denhardt's solution, and $100 \mu \mathrm{g}$ denatured $E$. coli $\mathrm{DNA} / \mathrm{ml} .(1 \times \mathrm{SSC}$ is $0.15 \mathrm{M} \mathrm{NaCl} / 0.15 \mathrm{M}$ sodium citrate buffer, $\mathrm{pH} 7.0 ; 1 \times$ Denhardt's solution contains $0.02 \%$ bovine serum albumin, $0.02 \%$ Ficoll, and $0.02 \%$ polyvinylpyrrolidone). For hybridization, a 5'-labeled oligonucleotide probe was added to the solution. Filters were washed for $5 \mathrm{~min}$ in $6 \times \mathrm{SSC} / 0.1 \% \mathrm{SDS}$ at $0^{\circ} \mathrm{C}$, followed by three successive 20 min washings in $3 \mathrm{M} \mathrm{Me}_{4} \mathrm{NCl}$ at $50^{\circ} \mathrm{C}$ as described by Wood. ${ }^{21}$ Positive colonies were detected by autoradiography at $-70^{\circ} \mathrm{C}$ with Fuji RX film and an intensifying screen

Northern blot analysis. RNA-blot analysis of 1 . lacteus poly $\left(\mathrm{A}^{+}\right) \mathrm{RNA}$ was done. RNA was denatured with glyoxal and dimethylsulfoxide and resolved by $1 \%$ agarose gel electrophoresis in $12 \mathrm{~mm}$ sodium acetate- $0.2 \mathrm{~mm}$ EDTA, pH 7.0. The RNA was transferred overnight to a nylon filter (Gene Screen Plus, Du Pont) with $10 \times \mathrm{SSC}$. The filter was dried at room temperature RNA blots were prehydridized at $60^{\circ} \mathrm{C}$ for $15 \mathrm{~min}$ in a hybridization buffer $(12.5 \%$ dextran sulfate, $1 \mathrm{M} \mathrm{NaCl}, 1 \%$ SDS, and $100 \mu \mathrm{g}$ denatured $E$. coli $\mathrm{DNA} / \mathrm{ml}$ ). Hybridization was done overnight at $60^{\circ} \mathrm{C}$ with the nick-translated cDNA as a probe. The filter was washed twice at room temperature with $2 \times \mathrm{SSC}$ and once at $60^{\circ} \mathrm{C}$ with $2 \times \mathrm{SSC} / 1 \% \mathrm{SDS}$ and once at room temperature with $0.1 \times \mathrm{SSC}$ for $1 \mathrm{hr}$ before drying and autoradiography.

\section{Results and Discussion}

\section{$N$-Terminal amino acid sequence of ILAP}

The $\mathrm{NH}_{2}$-terminal sequence of ILAP was found by Edman degradation to be A-A-G-SV-P-A-T-N-Q-L-V-D-Y-V-V-N-V-G-V-G-S$\mathrm{P}-\mathrm{A}$ - and used to design oligonucleotide probe for finding ILAP CDNA from the library.

\section{Isolation of a cDNA clone for ILAP}

A cDNA library in pBR322 was constructed and screened with a oligonucleotide probe corresponding to the amino acids from 13 to 18 of ILAP sequence (Fig. 1). From the 10,000 colonies screened, 300 positive clones were obtained. Recombinant plasmids from the selected colonies were prepared, digested with Pst $\mathbf{I}$, electrophoresed in agarose gel, and then transferred to nitrocellulose filters. Southern blot analysis showed that a clone, pILAP 4108 , had an insert of about 1.2 kilobase pairs that hybridized with the probe. The other clones 
had positive inserts of less than 0.8 kilobase pairs and they were insufficient in length to encode mature ILAP. Thus, the sequence of this clone with the longest insert (pILAP 4108) was analyzed.

\section{Nucleotide sequence analysis}

The insert from the clone was analyzed with a series of restriction enzymes. Figure 2 shows the restriction map and sequencing strategy. The nucleotide sequence of the insert is shown in Fig. 3 and the amino acid sequence of 340 residues of ILAP is deduced from the cDNA sequence. The $\mathrm{NH}_{2}$-terminal sequence deduced from the Edman degradation of the

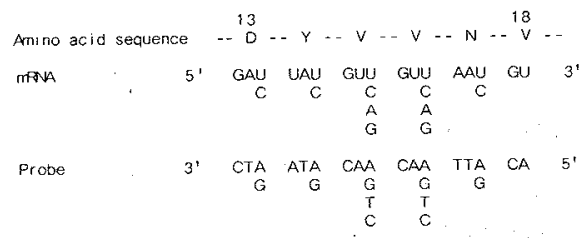

Fig. 1. Oligonucleotide Probe Used for Identifying ILAP CDNA. protein was found to start at residue 1 in Fig. 3 (starting at nucleotide 3 ). The $\mathrm{COOH}$-terminal position was found at $\mathrm{N} 340$ (nucleotides $1020 \sim 1022$ ) which immediately precedes a termination codon, TAG. The amino acid content from amino acid analysis agrees well with that calculated from the sequence data (Table I). Therefore, from these results, it is reasonable to conclude that this cDNA encodes ILAP.

The sequence analysis shows that the clone pILAP 4108 does not contain the entire pro-

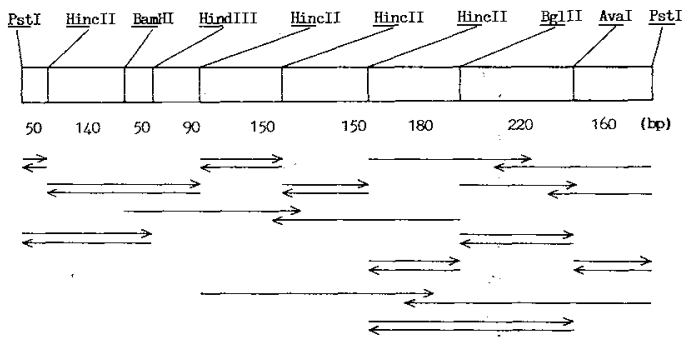

Fig. 2. Restriction Map and Sequencing Strategy of ILAP cDNA.

GT GOD GCT GAC AGC GTC DOC COC ACO AAC CAG CTC GTA GAC TAC GTT GTT AAC GT GOC GTC COC TOC COD COC 74 AOC ACT TAC TCT CTC TTG GTC GAT AOC GGT ADC TOG AAC AOC TGG CTC GGT OCT GAC AAG TCT TAT GTC AAG ACT 149 TOC AOC TOG TCT COG AOC AOC GAC AAA GTG TOC GTC AOC TAC GSA TOC GOC TOG TIC TCT GOC ACT GAA TAC ACT 224 $\underset{D}{G A C} A C C$ GTC ACT CIC OGA AOC TIG AOG ATC OOC AAG CAA TOC ATC GGT GIT GOC TOS CGT GAT AOC GGA TIC GAT 299 GGT GIT GAT GGT ATC CIC GGT GTC GAC OCT GTC GAC CII ACT GTC GGT AOC CTC AGC OOC CAC AOC TCT AOC TOC 374 ATC OOC ACT GTC AOC GAC AAC CTC TTC AGC COG GGC AOC ATC COC AOC AAC TIG CTC GOC GTC TOC TTC GAG COC 449

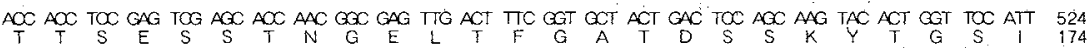
ACT TAC ACT COC ATC AOG AOC ACC TOC OOC GCG TCI GOG TAC TGG GGT ATT AAC CAG AOG ATT COC TAC COC TCT 599 TOC AOC TOC ATC CTC, TOC TOC AOC GOC GGT ATC GTC GAC ACT GOC AOC AOC CTC AOC CTC ATT CCT TCT GAT GCO 674 TTC GOC AAG TAC AAG AAG GCT ACT GGT GCT GIT GCT GAC AAC AAC ACT GGT: CTC TIG COC TIG ACC AOC GCT CAG 749

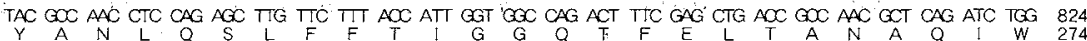
DOC OGT AAC CTG AAC AOG OCT ATT GGT GAC AOC GOC AGC AGT GTT TAC CTC ATC GTT GGT GAC CTC COC TOC GAC 899 $P$ R $N$ L N T A I G G S A S S V Y Y L I V G: D L G $\underset{S}{A B C} G G C$ GAG GGT CTC GAC TTC ATC AAC GGT TTG AOC TTC CTC GAG OGT TTC TAC TCT GTC TAC GAC AOC AOC AAC 974

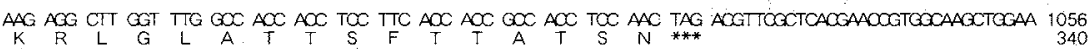
AaGGACSATGATGTACAATGGGTCGGATCATIGCACTGTTTATGGATATGTATCGTCTGTAACOSAATTGGATTTCGAATGSATTGTTGTATTGTT 1155 TTCTOCTAT

Fig. 3. Nucleotide Sequence and Deduced Amino Acid Sequence of ILAP cDNA.

$\mathrm{N}^{*}$, putative glycosylation site; $\mathrm{D}^{\sharp}$, active site aspartyl residue; ***, termination codon. The underline indicates the amino acid sequence which is coincident with the $\mathrm{N}$-terminal amino acid sequence found by Edman degradation of the purified ILAP. 
Table 1. Amino Acid Composition and Codon Usage of I. lacteus Milk-clotming Enzyme

\begin{tabular}{|c|c|c|c|}
\hline \multirow{2}{*}{ Amino acid } & \multicolumn{2}{|c|}{ No. of residues* } & \multirow{2}{*}{ No. of codons found } \\
\hline & A & B & \\
\hline \multirow[t]{2}{*}{$\mathrm{D}$} & & 18 & $13 \mathrm{GAC} 5 \mathrm{GAT}$ \\
\hline & 35 & & \\
\hline $\mathbf{N}$ & & 16 & $16 \mathrm{AAC}$ \\
\hline $\mathrm{T}$ & 53 & 55 & $32 \mathrm{ACC} 16 \mathrm{ACT} 7 \mathrm{ACG}$ \\
\hline $\mathbf{S}$ & 46 & 47 & 19 TCC 9 TCT 4 TCG 14 AGC 1 AGT \\
\hline \multirow[t]{2}{*}{$\mathrm{E}$} & & 7 & 6 GAG 1 GAA \\
\hline & 17 & & \\
\hline Q & & 8 & $7 \mathrm{CAG} 1 \mathrm{CAA}$ \\
\hline $\mathrm{P}$ & 11 & 11 & $10 \mathrm{CCC} 1 \mathrm{CCT}$ \\
\hline G & 37 & 36 & 19 GGT 14 GGC 3 GGA \\
\hline A & 27 & 26 & $11 \mathrm{GCC} 10 \mathrm{GCT} 5 \mathrm{GCG}$ \\
\hline $\mathrm{C}$ & 0 & 0 & \\
\hline M & 0 & 0 & \\
\hline $\mathrm{V}$ & 24 & 23 & 13 GTC 8 GTT 1 GTA 1 GTG \\
\hline I & 17 & 17 & 11 ATC 6 ATT \\
\hline $\mathrm{L}$ & 31 & 30 & 17 CTC 2 CTT 2 CTC 9 TTG \\
\hline $\mathrm{Y}$ & 14 & 14 & $13 \mathrm{TAC} 1 \mathrm{TAT}$ \\
\hline $\mathrm{F}$ & 12 & 13 & 12 TTC 1 TTT \\
\hline $\mathrm{K}$ & 8 & 9 & 8 AAG 1 AAA \\
\hline $\mathrm{H}$ & 1 & 1 & $1 \mathrm{CAC}$ \\
\hline $\mathbf{R}$ & 5 & 6 & $3 \mathrm{CGT} 2 \mathrm{CGC} 1 \mathrm{AGG}$ \\
\hline W & 2 & 3 & $3 \mathrm{TGG}$ \\
\hline Total & 340 & 340 & \\
\hline
\end{tabular}

* A, amino acid analysis; B, nucleotide sequence.

tein coding region. In addition, this clone neither contains the polyadenylation signal normally found in eukaryotic mRNA nor a poly(A) tail.

It is well known that aspartic proteinases have bilobal structures with a well-defined active site cleft. The two lobes comprise the $\mathrm{N}$ terminal and $\mathrm{C}$-terminal regions of these enzymes, and are topologically similar, indicating a possible mechanism in the evolution of aspartic proteinases by gene duplication and fusion. ${ }^{13)}$ The amino acid sequence of ILAP is compared with those of other aspartic pro- teinases, including penicillopepsin, porcine pepsin, and some milk-clotting enzymes, in Fig. 4. The aligned structures have identical residues in 20 positions. Most of them (15 residues) are in the $\mathrm{N}$-terminal region (residues $1 \sim 170$ ) of the structure and there are 5 residues in the C-terminal region, but the significance of this difference is not obvious. The sequence identity of ILAP with microbial milk-clotting enzymes such as endothiapepsin, Mucor pusillus and $M$. miehei aspartic proteinases were $26.2 \%, 22.6 \%$ and $22.4 \%$, respectively. The identity of ILAP with penicil-

Fig. 4. Alignment of ILAP with Other Aspartic Proteinases.

The numbering of residues is based on the penicillopepsin sequence. ILAP, Irpex lacteus aspartic proteinase; PEP, penicillopepsin ${ }^{14)}$; RHP, rhizopuspepsin ${ }^{15)}$; RNAP, Rhizopus niveus aspartic proteinase ${ }^{16)}$ ENP, endothiapepsin ${ }^{5)}$; MPAP, Mucor pusillus aspartic proteinase ${ }^{17)}$; MMAP, Mucor miehei aspartic proteinase ${ }^{18)}$; YPA, yeast proteinase $A^{193}$; POP, porcine pepsin ${ }^{20 ~ 22)}$; MOP, monkey pepsin ${ }^{23)}$; HUP, human pepsin ${ }^{24)}$; CHP, chicken pepsin ${ }^{25}$; POCD, porcine cathepsin $\mathrm{D}^{26)}$; HUCD, human cathepsin $\mathrm{D}^{27)}$; $\mathrm{MOG}$, monkey gastricsin $^{28)}$; BOC, bovine chymosin ${ }^{29 \sim 31)}$; HUR, human renin ${ }^{32,33)}$; MOR, mouse renin ${ }^{34,35)}$; RAR, rat renin. ${ }^{36)}$ 


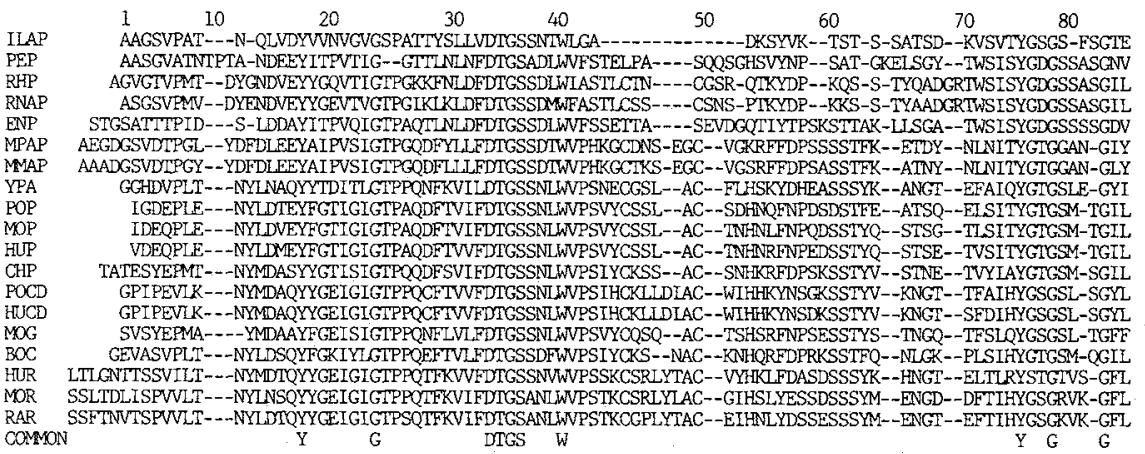
AYODTNVATDNDT

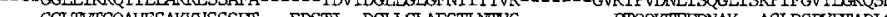

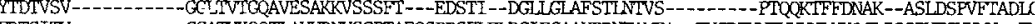
FRTSITV---------GCATVKQQTLAYVDNVSGPTAEQSPDSEU FLDGIFGAAYPDNTAMEA--EXGDTYNTVHVNLYKQGLISSPVFSVYMN--TN FEDSIAI---------GDITVIKQIIAYVDNVRGPTAEQSPNADIFLDGLFGAAYPDNIAMEA--EYGSTYNIVHVNLYKQGLISSPLFSVYMN--TN

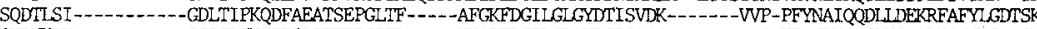

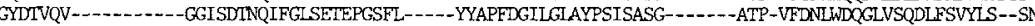

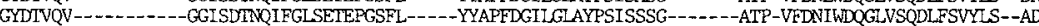
GYDIVOV---------GGISDTNDIFGISETEPGSFL-----YYAPFDGILGLAYPSISSSG-------ATP-VFDNIWNDGLVSQDLFSVYLS--AD

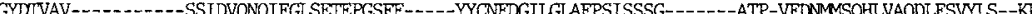
SODTSVPSN (1)

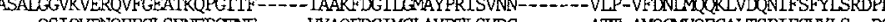
GYDILIV -

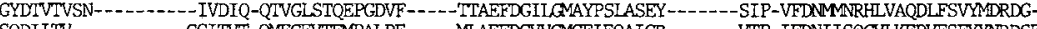
SQDII'TV-- - - - -GGITVT-QMFGEVTEMPALPF----MLAEFDGVGMGFIEQAIGR-----VTP-IFDNIISQGVLKEDVESFYYNRDSE

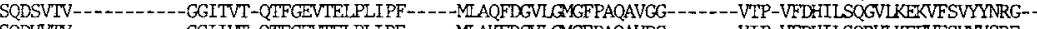

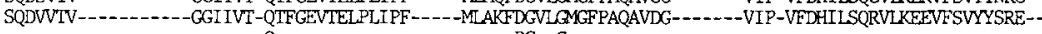
$\mathrm{Q}$

DG G

ILAP

RHP

RNAP

ENP

MPAP

MAP

YPA

MOP

HUP

GPP

HUCD

MOG

$\mathrm{BOC}$

HUR

RAR

COMON $G$

$\begin{array}{ccccccc}170 & 180 & 190 & 200 & 210 & 220 & 230\end{array}$

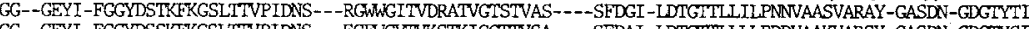

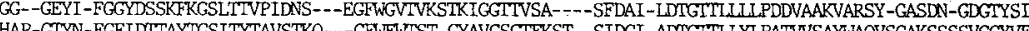

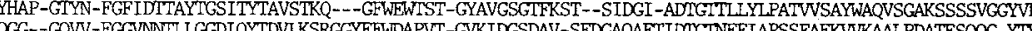

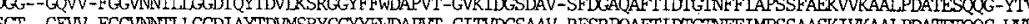

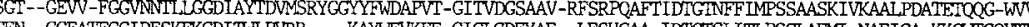
IEN--GGEATFGGIDESKFKGDITWL PVRR----KAYWEVKFE-GIGLGDEYAE--IESHGAA-IDTGTSLITLLSSGLAEMI-NAEIGA-KKGWIGQYTI DDS--GSWLI GGIDSSYYTGSLWWVVSV -- - -EGYWQITID-SITMDGETLA-CSGCCQAI-VUTGISLLTGPISAIAINIQSDIGA-SENSDGEYNI DQS--GSWIFGGIDSSYYTGSLNWVVVV----EGYWQISVD-SITMDGEAIA-CAEGCOAI-VDTGTSLLIGPTSPIANI-QSDIGA-SENSDGEMVN DQS--GSWIFGGIDSSYYTGSLWWPVTV----EGYWQITVD-SITMNGEAIA-CAEGCOAI-VDTGTSLLTGPTSPIANI-QSDIGA-SENSDGDMVV GET--GSFVLFGGIDPNYTIKGIYWNPSA----ETYWQITMD-RVTVGNKYVA-CFFTCQAI-VDTGTSLLWMPQGAYNRI-IKDLGV-S--SDGE--I AQP--GGEIMI GGIDSKYYKGSLDYHNVIR----KAYWQIHMN-QVAVGSSLTL-CKGGCEAI-VDTGTSLIVGQFEEVREL-GKAIGA-VPLIQGEYM AQP--GGELMEGTDSKYYKGSISYLNVIR----KAYWQVHLD-QVEVASGLTL-CKEGCEAI-VDTGTSLMVGPVDEVREL-QKAIGA-VPLIOGEYMI QGS-SGGAVWGGVDSSLYTCQIYWAPVTQ----ELYWQIGIE-EFLIIGGQASGWCSECCQAI-VDTGTSLLTVPQQYMSAL-LQATGA-QEDEYGQFLV 0----ESMLTLGAIDPSYYTGSIHWVVTV-.--0QYWOFYVD-SVTISGWWA-CEGCCOAI-IDTGTSKLVGPSSDILNI-DOAIGA-TONDYDEFTI

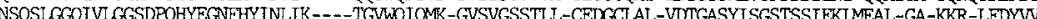
-SHELGGEVLGGSDPOHYOGNFHYVISK----AGSWOITMK-GVSVGPATLL-CEEGCMGV-VITGTSYISGYTSSIOLIMOAL-GVKEKR-ANMYW W DTG
250 260
270
280
290
300
310
320

ILAP TTAQYANLSLFFIIGCQIFELTANAQIWPRNLNTAIGGSASSVYIVGDLG------SDSGEGLDFINGLTFLERFYSVYTTTNR-IGLATTSFTTATSN

PEP DCS-SSIPDFSVSISGYTATVPGSLINYGPSGNGST--------CLCGIQ------SNSGIGF -SIFGDIFIKSQYVVDSDGPQ-IGFAPQA

RNAP TCDT-SRFKPLVSINGASFOVSPDSLVFEE---YQGQ------CIAGF------GYGNFDFAI IGDTFLKNNYVENQGVPE-VQIAPVAQ

ENP PCSA--TIPSFTFGOSAREVSDSLIFE---DGNK-------CIAGF-------AAG-GOLAILGDVELKNNYVVNQEVPE-VQLAPVAQ

PCSA--TLPSFTFGUGSARIVIFGDYIDFGPISTGSSS------CEGGIQ-----SSAGIGI-NIFGDVALKAAFVVFNGATIPTIGFASK

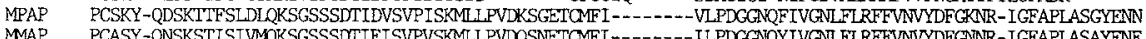

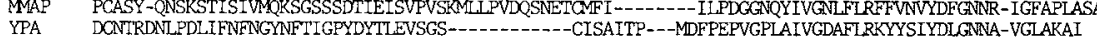

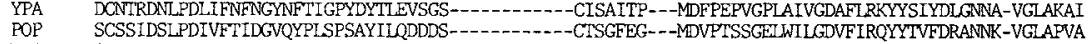

MOP SCSAISSLPDIVFTINGIQYPVPPSAYILQSQGS-_........-CTSGFQG---MDVPTESGELWILGODVIRQYFTVFDRANNQ-VGLAPVA

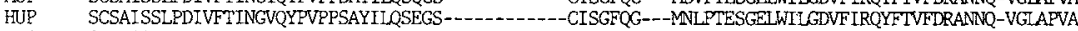

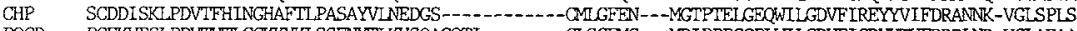

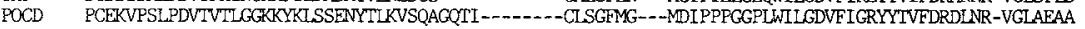

HUCD PCEKVSTLPAITLKLCGKGYKLSPEDYTL KVSQAGKIL-------CLSGFMG---MDIPPPSGPLWLLGVVIGRYYVFDRDNNR-VGFAEAARL

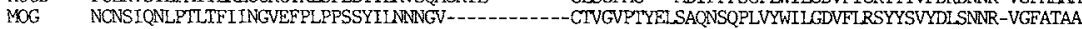

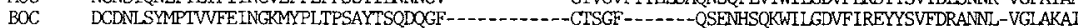

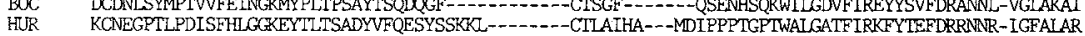

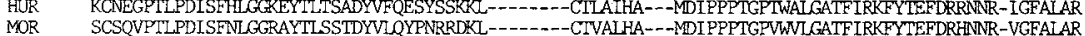

RAR NCSQVYILPDISFYLGGRTYILSNMDYVQKNPFRNDDL--...-CILALOG---LDIPPPTGPVWLGATFIRKFYTEFDRHNMR-IGFAIAR 
lopepsin was $28.2 \%, 28.5 \%$ with rhizopuspep$\sin$, and $27.1 \%$ with porcine pepsin. The amino acid residues in ILAP identical to those in penicillopepsin, rhizopuspepsin or porcine pepsin are distributed through out the molecules, which suggests that the tertiary structure of ILAP should be similar to those of penicillopepsin, rhizopuspepsin, and porcine pepsin.

Compared with the sequence of penicillopepsin, there is a deletion of 10 residues (around the 50th residue) and two insertions of 5 residues (around the 150 th and 165th residues) in the $\mathrm{N}$-terminal region and one insertion of 10 residues (between the 280 th and 290 th residues) in the C-terminal region of ILAP. The regions which correspond to the residues $40 \sim 60$ and $270 \sim 290$ in penicillopepsin are appreciably variable among aspartyl proteinases. These regions are on the surface of the penicillopepsin molecule away from the active site cleft and are though to be unimportant for activity. ${ }^{13.14)}$ Accordingly, it can be inferred that the large deletions and insertions in ILAP occur in these variable regions.

The inactivation of ILAP by active-site directed reagents of pepsin such as DAN and EPNP has implied that the catalytic apparatus of ILAP is similar to those of aspartic proteinases. ${ }^{1)}$ Comparison of the sequence of ILAP with those of other aspartic proteinases suggests that the regions $33 \sim 36$ and $213 \sim 215$ in penicillopepsin are highly conserved among those enzymes and D 32 and D 212 in ILAP are the active site aspartic acid residues. $Y 75$ (Y 63 in the ILAP sequence) is though to be the residue that participates in the catalytic mechanism, ${ }^{37)}$ and the residues from $75 \sim 79$ are also well conserved among aspartic proteinases including ILAP.

The molecular weight of ILAP calculated from the predicted sequence was 35,000 and two putative $N$-glycosylation sites, N-X-T, were found at 192 and 238. This molecular weight is apparently smaller than that found by SDS-PAGE $(39,000)$. The difference seems to be attributed to its sugar chain which can be attached to Asn 192 and/or Asn 238. ILAP seems to have one or two sugar chains, because ILAP shows an affinity towards various kinds of lectins including concanavalin $\mathrm{A}$, wheat germ agglutinin, and Ricinus communis agglutinin (data not shown). From the alignment shown in Fig. 4, it seems that the two putative glycosylation sites of ILAP can be located on the surface of the molecule, because the regions near 190 and 240 in penicillopepsin are exposed to the atmosphere. ${ }^{13)}$

One striking feature of the amino acid composition of ILAP is the high content of $\mathrm{T}$ and $\mathrm{S}$, like endothiapepsin. Contents of $\mathrm{T}$ and $\mathrm{S}$ of endothiapepsin and ILAP were calculated to be $29 \%$ and $30 \%$, respectively, and for both residues they are double the average values for other proteins. ${ }^{5}$ )

The other striking feature of ILAP is the absence of cysteine and methionine in its primary structure. This suggests that ILAP is the first aspartic proteinase which contains no disulfide bridge in the molecule. It is interesting to note that the number of disulfide bonds is thrae in vertebrate aspartic proteinase, two in rhizopuspepsin, Mucor pusillus as-

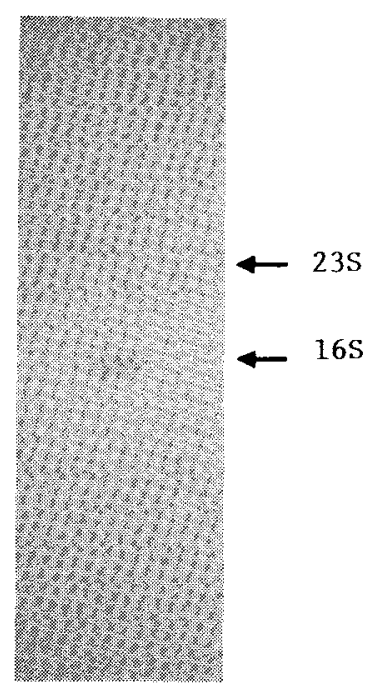

Fig. 5. Northern Blot Analysis of I. lacteus Poly $\left(\mathrm{A}^{+}\right)$ RNA.

$5 \mu \mathrm{g}$ of mRNA were separated on a $1 \%$ agarose gel, blotted to nylon filter, and hydridized with nick-translated whole insert of pILAP 4108. 
partic proteinase, Mucor miehei aspartic proteinase, and yeast proteinase A, one in endothiapepsin and penicillopepsin, and none in ILAP. The lack of disulfide bridges might be one of the reasons why ILAP is so unstable above neutral $\mathrm{pH}^{2)}$

As shown in Table I, codon use for ILAP has a preference for codons ending with $\mathrm{C}$ or $\mathrm{G}$. Such codon usage has been observed in mammalian genes. $^{28)}$

\section{Northern blot hybridization}

Since pILAP 4108 neither contains the $5^{\prime}$ coding region (preprosequence) nor the $3^{\prime}$ noncoding region including a poly(A) tail, we tried to estimate the size of ILAP mRNA. A RNA blot hybridization of the purified poly $\left(\mathrm{A}^{+}\right) \mathrm{RNA}$ with a whole insert of pILAP 4108 as a probe revealed the mRNA size of ILAP to be about 1.5 kilo-nucleotides (Fig. 5). Thus the sum of the missing $5^{\prime}$ and $3^{\prime}$ regions of the mRNA is about 300 nucleotides.

\section{References}

1) H. Kobayashi, I. Kusakabe and K. Murakami, Agric. Biol. Chem., 47, 551 (1983).

2) E. Kikuchi, H. Kobayashi, I. Kusakabe and K. Murakami, Agric. Biol. Chem., 52, 1277 (1988).

3) E. Kikuchi, H. Kobayashi, I. Kusakabe and K. Murakami, Jpn. J. Zootech. Sci., 59, 532 (1988).

4) H. Kobayashi, I. Kusakabe and K. Murakami, Agric. Biol. Chem., 49, 1605 (1985).

5) V. Barkholt, Eur. J. Biochem., 167, 327 (1987).

6) U. K. Laemmli, Nature, 227, 680 (1970).

7) D. T. Davis, Ann. N. Y. Acad. Sci., 121, 404 (1964).

8) B. Penke, R. Ferenczi and K. Kovacs, Anal. Biochem., 60, 45 (1974).

9) U. Gubler and B. J. Hoffman, Gene, 25, 263 (1983).

10) R. Roychoudhury and $R$. Wu, in "Methods in Enzymology," Vol. 65, ed. by L. Grossman and K. Moldave, Academic Press, New York, 1980, pp. $43 \sim 62$.

11) D. Hanahan, J. Mol. Biol., 166, 557 (1983).

12) W. I. Wood, J. Gilschier, L. A. Lasky and R. M. Lawn, Proc. Natl. Acad. Sci. U.S.A., 82, 1585 (1985).

13) J. Tang. M. N. G. James, I. N. Hsu, J. A. Jenkins and T. L. Blundell, Nature, 271, 618 (1978).

14) M. N. G. James and R. Sielecki, J. Mol. Biol., 163, 299 (1983).

15) K. Takahashi, J. Biol. Chem., 262, 1468 (1987).
16) H. Horiuchi, K. Yanai, T. Okazaki, M. Takagi and K. Yano, J. Bacteriol., 170, 272 (1988).

17) N. Tonouchi, H. Shoun, T. Uozumi and T. Beppu, Nucl. Acids Res., 14, 7557 (1986).

18) E. Boel, A. Bech, K. Randrup, B. Draeger, N. P. Ful and B. Foltman, Proteins, 1, 363 (1986).

19) C. A. Woolford, L. B. Daniels, F. J. Park, E. W. Jones, J. N. Van Arsdell and M. A. Innis, Mol. Cell. Biol., 6, 2500 (1986).

20) J. Tang, P. Sepulveda, J. Marciniszyn, Jr., K. C. S Chen, W-Y, Huang, N. Tao, D. Liu and J. P. Lanier, Proc. Natl. Acad. Sci. U.S.A., 70, 3437 (1973).

21) P. Sepulveda, J. Marciniszyn, Jr., D. Liu, and J. Tang, J. Biol. Chem., 250, 5082 (1975).

22) L. Moravek and V. Kostka, FEBS Lett., 43, 207 (1974).

23) T. Kageyama and K. Takahashi, J. Biol. Chem., 261, 4395 (1986).

24) K. Sogawa, Y. Fujii-Kuriyama, Y. Mizukami, Y. Ichihara and K. Takahashi, J. Biol. Chem., 258, 5306 (1983).

25) M. Baudys and V. Kostka, Eur. J. Biochem., 136, 89 (1983).

26) J. G. Shewale and J. Tang, Proc. Natl. Acad. Sci. U.S.A., 81, 3703 (1984).

27) P. L. Faust, S. Kornfeld and J. M. Chirgwin, Proc. Natl. Acad. Sci. U.S.A., 82, 4910 (1985).

28) T. Kageyama and K. Takahashi, J. Biol. Chem., 261, 4406 (1986).

29) B. Foltman, V. B. Pedersen, H. Jacobsen, D. Kauffman and G. Wybrandt, Proc. Natl. Acad. Sci. U.S.A., 74, 2321 (1977).

30) B. Foltman, V. B. Pedersen, D. Kauffman and G. Wybrandt, J. Biol. Chem., 254, 8447 (1979).

31) T. J. R. Harris, P. A. Lowe, A. Lyons, P. G. Thomas, M. A. W. Eaton, T. A. Millican, T. P. Patel, C. C. Bose, N. H. Carey and M. T. Boel, Nucl. Acids Res., 10, 2177 (1982).

32) T. Imai, H. Miyazaki, S. Hirose, H. Hori, T. Hayashi, R. Kageyama, H. Okubo, S. Nakanishi and K. Murakami, Proc. Natl. Acad. Sci. U.S.A., 80, 7405 (1983).

33) P. M. Hobart, M. Fogliano, B. A. O'Connor, I. M. Schaefer and J. M. Chirgwin, Proc. Natl. Acad. Sci. U.S.A., 81, 5026 (1984).

34) J-J. Panthier, S. Foote, B. Chambraud, A. D. Strosberg, P. Corvol and F. Rougeon, Nature, 298, 90 (1982).

35) K. S. Misono, J.-J. Chang and T. Inagmi, Proc. Natl. Acad. Sci. U.S.A., 79, 4858 (1982).

36) A. Fukamizu, K. Nishi, T. Cho, M. Saito, K. Nakayama, H. Okubo, S. Nakanishi and K. Murakami, J. Mol. Biol., 201, 443 (1988).

37) L. Pearl and T. Blundell, FEBS Lett., 174, 96 (1984).

38) R. Grantham, C. Gautier, M. Gouy, R. Merder and A. Pave, Nucl. Acids Res., 8, r49 (1980). 